\title{
Análise dos Processos Éticos Publicados no Jornal do Conselho Federal de Psicologia
}

\author{
Priscila Zaia Karina da Silva Oliveira \\ Pontifícia Universidade Católica de Campinas, SP, Brasil. $\quad$ Pontifícia Universidade Católica de Campinas, SP, Brasil. \\ Tatiana de Cássia Nakano \\ Pontifícia Universidade Católica de Campinas, SP, Brasil.
}

\begin{abstract}
Resumo: A importância dos Conselhos Regionais e do Conselho Federal de Psicologia relacionase com as tentativas de zelo com o cumprimento integral das práticas éticas da profissão. Neste sentido, o objetivo principal do presente estudo foi analisar os processos éticos publicados no período de 2004 a 2016 no Jornal do Federal. Foram avaliadas 26 edições, as quais apresentaram 286 infrações na seção intitulada "Processos Éticos". Os resultados apontaram que a região 8, referente ao estado do Paraná, demonstrou maior incidência de processos éticos por psicólogos inscritos. Quanto ao conteúdo das ementas, identificou-se 35 categorias diferentes, sendo a mais comum sobre processos éticos profissionais. Destaca-se que os três números mais recentes da revista apresentaram com maior clareza o conteúdo das ementas, tornando possível verificar que dos 57 processos éticos descritos, 34 foram relacionados à área da avaliação psicológica, representando $60 \%$ do total dos respectivos números. O último dado analisado mostrou a decisão dos Conselhos Regionais e do Conselho Federal, sendo a mais comum para ambos o arquivamento dos processos. Conclui-se que há uma demanda de ações voltadas à formação e à prática de profissionais Psicologia, em especial da área de Avaliação Psicológica.
\end{abstract}

Palavras-chave: Ética, Normas Profissionais, Atuação do Psicólogo, Avaliação Psicológica.

\section{Analysis of Ethical Claims Published in the Psychology's Federal Council Journal}

Abstract: Federal and Regional Councils of Psychology are important agencies dedicated in promoting and monitoring ethical practices. In this sense, the purpose of this paper was to analyze ethical claims published between 2004 and 2016 in Jornal do Federal, a Journal of the Federal Council of Psychology. Twenty-six issues were analyzed, in which there were 286 published offences in the section entitled "Ethical Claims". Results showed that the state of Paraná (region 8), had higher incidence of ethical processes considering the number of registered psychologists. On the amendments contents, 35 different categories were identified, and the most common was about ethical practice. Tree most recent issues of this journal showed more clearly the amendments' contents, making it possible to understand that psychological assessment is a common ethical problem among psychologists. Figuring $60 \%$ of the ethical claims on these last three issues. We also analyze Regional and Federal's Councils final decisions, and it shows that the most frequently decision was on archiving the processes. After all those analyses, it is possible to state that there are many actions towards on training, as well as guiding psychologists practices.

Keywords: Ethics, Professional Guidelines, Psychologists Practices, Psychological Assessment. 


\title{
Análisis de los Procesos Éticos Publicados en el Diario del Consejo Federal de Psicología
}

\begin{abstract}
Resumen: La importancia de los Consejos Regionales y el Consejo Federal de Psicología se refiere a los intentos celosos a plena conformidad con las prácticas éticas de la profesión. En este sentido, el objetivo principal de este estudio fue analizar los procedimientos éticos publicados en el período de 2004 a 2016 en el Diario Federal, una publicación del Consejo Federal de Psicología. Se evaluaron 26 números, que registró 286 delitos en la sección titulada "Proceso de Ética". Los resultados mostraron que la región 8, en relación con el estado de Paraná, mostró una mayor incidencia de procesos éticos considerando el número de psicólogos registrados. En cuanto al contenido de los procesos, se identificaron 35 categorías diferentes, los más comunes en los procesos de ética profesional. Cabe destacar que las tres publicaciones más recientes mostraron más claramente el contenido de los procesos, por lo que fuera posible verificar que de los 57 procedimientos éticos encontrados, 34 estaban relacionados con el campo de la evaluación psicológica, número que representa $60 \%$ de los procesos. Los últimos datos analizados mostraron que la decisión más frecuente de los Consejos Regionales y el Consejo Federal es el proceso de archivo. Llegamos a la conclusión de que existe una demanda de acciones de capacitación y ejercicio de profesionales de la psicología, especialmente en evaluación psicológica, que sigue siendo necesaria.
\end{abstract}

Palabras clave: Ética, Normas Profesionales, Funciones del Psicólogo, Evaluación Psicológica.

\section{Introdução}

Ao longo da história da Psicologia no Brasil, é possível observar que o avanço da profissão e da ciência psicológica se encontra intrinsicamente contextualizado ao momento político e sociocultural do país (Rechtman, 2015). Das primeiras disciplinas de Psicologia nas faculdades de ciências médicas até a estruturação atual da profissão como se tem hoje, ocorreram incontáveis reflexões teóricas e práticas a fim de promover o crescimento e fortalecimento da área enquanto ciência e profissão (Soares, 2010). Ainda segundo o autor, as primeiras contribuições foram realizadas por meio das teses de doutoramento, com foco nas áreas de neuropsiquiatria, psicofisiologia, neurologia e educação, as quais subsidiaram o desenvolvimento da Psicologia. Segundo Pereira e Pereira Neto (2003), apesar deste movimento em prol do seu desenvolvimento, a profissão ainda não havia alcançado um caráter institucionalizado e sistematizado, ou seja, a área ainda não era considerada uma prática regulamentada até a década de 1960.

Aproximadamente 40 anos se passaram entre os primeiros esforços para a construção da Psicologia até a promulgação da Lei no 4.119 que a regulamentou como profissão, em 27 de agosto de 1962. Cabe ressaltar que foram necessários ainda outros nove anos entre a aprovação da referida lei e a criação dos Conselhos Regionais e do Conselho Federal, por meio da Lei no 5.766, de 20 de dezembro de 1971 (Bastos, \& Gomide, 1989; Soares, 2010). Tais conselhos são considerados instâncias de representação máxima dos profissionais da área (Holanda, 1997), aos quais cabem as funções de orientar, disciplinar, fiscalizar e zelar pelo cumprimento das práticas éticas na profissão. Por ser o órgão fiscalizador da profissão, o Conselho Federal de Psicologia (CFP) tem, dentre suas atribuições, a responsabilidade de garantir a qualidade técnica e ética dos serviços prestados pelos psicólogos (Anache, \& Corrêa, 2010). Sua atuação, no entanto, não se limita, ainda de acordo com as autoras, à fiscalização. Ele consiste em uma instância, cujo objetivo maior é o de promover o debate e construir diretrizes que orientem as práticas dos psicólogos, dentro de um diálogo constante com a sociedade sobre o trabalho do profissional dessa área.

Dentro do sistema Conselhos (regionais ou federal), podemos enfatizar que a primeira ação desses órgãos tem sido a de orientar, valorizar virtudes, princípios e diretrizes, de maneira a contribuir para o desenvolvimento da Psicologia enquanto ciência 
e profissão, conduzindo-a de acordo com padrões legais, éticos e profissionais (Tavares, 2010). Para isso, ainda de acordo com o autor, atuam como mediadores entre a sociedade, a Psicologia, os usuários, os psicólogos, os profissionais de outras áreas e as diferentes instituições. Nesse contexto, "as sanções são aplicadas somente nos casos em que as ações de orientação não são suficientes para corrigir as situações que ferem direito de pessoas ou o bem-estar da sociedade, nos casos de dano por omissão, negligência, imprudência ou imperícia" (p. 38).

Assim, um papel fundamental dos Conselhos relaciona-se à fiscalização e ao zelo pelo cumprimento integral das práticas éticas. Para isso, o Código de Ética Profissional, o qual postula os princípios éticos a serem adotados pelos profissionais de cada área, surgiu como parâmetro para regular o conjunto de condutas profissionais e para proteger os interesses das pessoas. Por conta das mudanças ocorridas nos diferentes períodos da história do país e da própria Psicologia, diante da necessidade de responder às transformações da sociedade brasileira, a Psicologia encontra-se em seu quarto código, os quais forma publicados, respectivamente, em 1975, 1979, 1987, 2005, ainda em vigor (Anache, \& Reppold, 2010). "Considerando que a prática do psicólogo se encontra regulada por um código de ética profissional, a sua violação expressa a crença de que ele não agiu de acordo com os princípios e as normatizações de sua profissão" (p. 68).

O processo de investigação das faltas éticas ocorre a partir de denúncias contra psicólogos que infrinjam o Código de Ética Profissional ou que cometam faltas disciplinares. Tais denúncias envolvem a atuação destes profissionais em todo território nacional e são realizadas por qualquer pessoa que se sinta lesada. Nesse sentido, deve-se apresentar ao Conselho Regional de Psicologia (CRP) em que o psicólogo denunciado estiver inscrito, um documento redigido pelo representante da acusação com os seguintes dados: nome e qualificação de quem denuncia; nome e qualificação do profissional denunciado; descrição detalhada do fato; provas documentais que possam auxiliar no processo de apuração e quaisquer meios existentes que sustentem o que é alegado. Ainda que a apresentação de tais documentos não ocorra, a representação da denúncia pode ser oficializada (http://site.cfp.org.br/ servicos/orientacao-e-etica/processos-eticos/).

Cabe a cada jurisdição regional investigar as denúncias, mantendo sob sigilo seu conteúdo, a fim de apurar os fatos, com base nos elementos que constam na representação. As denúncias são encaminhadas à Comissão de Ética de cada região e a esta cabe solicitar esclarecimentos teóricos e técnicos ao psicólogo denunciado. Tais esclarecimentos são compreendidos como a defesa prévia do psicólogo, que deverá ocorrer no prazo de 15 dias, após a notificação. Também é responsabilidade desta comissão apreciar toda documentação enviada, assim como redigir um parecer a respeito da conduta ética investigada. Como resultado desta análise, a comissão poderá recomendar a exclusão da representação, a mediação das partes envolvidas ou ainda, a instauração do processo ético disciplinar (Resolução CFP no 006/2007 [Conselho Federal de Psicologia, 2007]).

O parecer elaborado pela Comissão de Ética é encaminhado aos conselheiros regionais que, em reunião plenária, decidirão se o processo ético será instaurado ou arquivado. Caso a decisão seja pela instauração do processo, haverá outra reunião plenária dos conselheiros com as partes envolvidas no processo de acusação, possibilitando nova defesa do acusado. É importante informar que a decisão é tomada mediante o voto dos conselheiros e, em caso de condenação, estes poderão aplicar as seguintes penalidades: advertência, multa, censura pública, suspensão do exercício profissional por até 30 dias ou cassação do exercício profissional ${ }^{1}$. Após a decisão proferida pelo CRP, o profissional denunciado possui o prazo de 30 dias para recorrer. Ao CFP cabe, em sessão sigilosa com os conselheiros e as partes envolvidas, verificar os recursos e determinações propostas pela jurisdição regional, sendo possível que as decisões sejam mantidas ou reformadas ${ }^{2}$. Posteriormente ao julgamento de cada caso, os resultados dos processos são publicados no jornal do CFP, em uma seção intitulada "Processos Éticos". Tendo em vista a complexidade dos procedimentos envolvidos na análise e instauração de pro-

\footnotetext{
${ }^{1}$ Conselho Regional de Psicologia 6a Região. Recuperado de http://www.crpsp.org.br/portal/comunicacao/jornal_crp/144/frames/ fr_questoes_eticas.aspx

${ }^{2}$ Conselho Federal de Psicologia. Recuperado de http://site.cfp.org.br/servicos/orientacao-e-etica/processos-eticos/
} 
cessos éticos, sugere-se, para maior detalhamento, a visualização da Resolução $\mathrm{n}^{\circ}$ 006/2007 (CFP, 2007), a qual institui o Código de Processamento Disciplinar. Em seu parágrafo $2^{\circ}$, a citada resolução esclarece que "A censura pública, a suspensão e a cassação do exercício profissional serão publicadas em Diário Oficial, jornais ou boletins do Conselho Regional e afixados na sua sede onde estiver inscrito o psicólogo processado e nas suas Seções".

Considerando a importância de compreender todo o processo de instauração de uma falta ética, é possível observar que a conduta dos profissionais em Psicologia tem sido foco do interesse de pesquisadores (Anache, \& Reppold, 2010). Dessa forma, ao analisar as principais infrações éticas cometidas pelos psicólogos inscritos no Conselho Regional 8 (Paraná), no período de 1994 a 2003, Frizzo (2004) constatou que a maioria das infrações denunciadas se referiam ao exercício da avaliação psicológica. Dentre os principais motivos das denúncias destacam-se, principalmente, o uso de testes aplicados, a análise das informações obtidas por meio desses instrumentos e as razões que levaram o psicólogo a conduzir uma avaliação psicológica. Portanto, é possível afirmar que a criação do Sistema de Avaliação dos Testes Psicológicos (Satepsi) se dá diante da observação de uma grande quantidade de processos éticos envolvendo a avaliação psicológica (Primi, \& Nunes, 2010), fato este que motivou a realização da presente pesquisa.

Perante as mudanças que a área vem enfrentando e as necessidades enfatizadas pelos pesquisadores, o presente estudo teve como objetivo analisar os processos éticos, elencados pelo CFP, a fim de obter dados acerca dos problemas e dificuldades que ainda marcam a atuação na área.

\section{Método}

\section{Material}

Um total de 286 infrações apresentadas na seção intitulada "Processos Éticos", provenientes de 26 edições do Jornal do Federal, publicadas entre os anos de 2004 e 2016, foi selecionado pelas autoras para compor o material a ser analisado.

\section{Procedimentos}

Inicialmente um levantamento de todos os números do Jornal do Federal, publicação de respon- sabilidade do CFP, foi realizado, visando-se identificar aqueles que se encontravam disponíveis no site do referido órgão (http://site.cfp.org.br/). Como resultado, 35 números foram encontrados (números 77 a 112), sendo que, no entanto, nove deles não foram utilizados na pesquisa por diferentes motivos (os números 77 e 78 apresentaram apenas as capas em formato pdf sem nenhum conteúdo; os números 79, 80, 81, 88 e 104 não relatavam processos éticos; e os números 93 e 94 apresentaram problemas no arquivo em formato pdf, não sendo possível sua visualização).

Diante da impossibilidade de acesso virtual às edições citadas, tentativas de acesso aos materiais indisponíveis junto às instâncias regionais e à instância federal do Conselho de Psicologia foram realizadas, mas sem sucesso, visto que tais números não estavam disponíveis nos acervos físicos das referidas instâncias. Assim, dos 35 exemplares encontrados, 26 deles tiveram suas infrações éticas analisadas, em um total de 286 processos.

A segunda etapa consistiu na tabulação de todos os processos éticos encontrados na seção dedicada à apresentação destes no Jornal do Federal, sendo que as informações disponíveis eram referentes ao número do processo, região de origem do CRP, ementa a que pertence o processo, assim como a apresentação da decisão do CRP e CFP, data do julgamento e autoridades presentes. Convém salientar que, nos exemplares 82 ao 89, a informação relacionada aos artigos infringidos no Código de Ética de Psicologia era apresentada, todavia, a partir do número 90 até o 111, o detalhamento de incisos deixou de ser exibido. Cabe destacar que, segundo as informações apresentadas no site do Conselho Federal de Psicologia (http://site. cfp.org.br/servicos/orientacao-e-etica/duvidas-frequentes-de-orientacao-e-etica/), os processos éticos são tratados de forma sigilosa, de modo que não há a possibilidade de divulgação detalhada dos conteúdos, bem como a identificação do nome do profissional que está sendo julgado.

Após a seleção dos casos, o processo de análise dos dados obtidos envolveu o levantamento da frequência e a porcentagem dos processos éticos, considerando-se cada CRP do país, a prevalência de faltas éticas correspondentes ao número de profissionais inscritos em cada região, a frequência das ementas infringidas, bem como o artigo do código de ética que foi violado (naqueles que apresentaram tal informação) e as decisões dos CRP e CFP. Considerando-se 
que os últimos três números do Jornal do Federal, por apresentarem conteúdo de ementas mais detalhado, a análise qualitativa desse dado também foi realizada.

\section{Resultados}

Destaca-se que o país conta, por ocasião do levantamento dos dados (maio de 2016), com 266.536 profissionais inscritos nos 23 CRPs, de maneira que as
286 infrações encontradas indicam uma proporção estimada de uma infração para cada 961 profissionais. A fim de compreender a frequência de faltas éticas em cada Conselho Regional, bem como, estimar a prevalência de processos éticos, considerando-se ainda o número de profissionais inscritos em cada região, procedeu-se com a primeira análise. Os dados encontram-se descritos na Tabela 1.

Tabela 1

Frequência e prevalência de faltas éticas por conselho regional.

\begin{tabular}{|c|c|c|c|c|c|c|}
\hline $\begin{array}{l}\text { Número do } \\
\text { Conselho } \\
\text { Regional }\end{array}$ & Unidade Federativa & $\begin{array}{l}\text { Frequência de } \\
\text { faltas éticas } \\
\text { encontradas }\end{array}$ & $\begin{array}{l}\text { Percentual } \\
\text { por estado }\end{array}$ & $\begin{array}{l}\text { Número de } \\
\text { psicólogos } \\
\text { inscritos em } \\
\text { cada estado* }\end{array}$ & $\begin{array}{l}\text { Prevalência } \\
\text { de processos } \\
\text { éticos** }\end{array}$ & Porcentagem ${ }^{* * *}$ \\
\hline 1 & Distrito Federal & 7 & 2,45 & 8.272 & 1: 1182 & 0,08 \\
\hline 2 & Pernambuco & 3 & 1,05 & 9.478 & $1: 3159$ & 0,03 \\
\hline 3 & Bahia & 13 & 4,55 & 9.897 & $1: 761$ & 0,13 \\
\hline 4 & Minas Gerais & 17 & 5,94 & 31.491 & 1: 1852 & 0,05 \\
\hline 5 & Rio de Janeiro & 20 & 6,99 & 34.406 & 1: 1720 & 0,06 \\
\hline 6 & São Paulo & 107 & 37,41 & 87.272 & $1: 816$ & 0,12 \\
\hline 7 & Rio Grande do Sul & 15 & 5,24 & 18.436 & 1: 1229 & 0,08 \\
\hline 8 & Paraná & 43 & 15,03 & 15.455 & $1: 359$ & 0,28 \\
\hline 9 & Goiás & 8 & 2,80 & 6.835 & $1: 854$ & 0,12 \\
\hline 10 & Pará e Amapá & 2 & 0,70 & 4.134 & 1: 2067 & 0,05 \\
\hline 11 & Ceará & 13 & 4,55 & 5.316 & 1: 409 & 0,24 \\
\hline 12 & Santa Catarina & 23 & 8,04 & 10.827 & $1: 471$ & 0,21 \\
\hline 13 & Paraíba & 1 & 0,35 & 3.948 & 1: 3948 & 0,03 \\
\hline 14 & Mato Grosso do Sul & 4 & 1,40 & 3.514 & 1: 879 & 0,11 \\
\hline 15 & Alagoas & - & - & 3.248 & - & - \\
\hline 16 & Espírito Santo & 9 & 3,15 & 4.121 & 1: 458 & 0,22 \\
\hline 17 & Rio Grande do Norte & 1 & 0,35 & 2.557 & $1: 2557$ & 0,04 \\
\hline 18 & Mato Grosso & - & - & 2.772 & - & - \\
\hline 19 & Sergipe & - & - & 1.896 & - & - \\
\hline 20 & $\begin{array}{l}\text { Amazonas, Acre, } \\
\text { Roraima e Rondônia }\end{array}$ & - & - & 5.955 & - & - \\
\hline 21 & Piauí & - & - & 2.241 & - & - \\
\hline 22 & Maranhão & - & - & 1.809 & - & - \\
\hline 23 & Tocantins & - & - & 1.053 & - & - \\
\hline Total & & 286 & 100 & 933 & $1: 961$ & 0,10 \\
\hline
\end{tabular}

Dados coletados em 2 de maio de 2016; *número de psicólogos do Brasil inscritos nos Conselhos Regionais; **faltas por número de psicólogos; ${ }^{* * *}$ porcentagem estimada a partir do número de infrações encontradas dividido pelo número de psicólogos inscritos em cada região. 
Tomando-se os números absolutos de faltas éticas cometidas pelos psicólogos de cada região (na coluna Frequência de faltas éticas encontradas), pode-se verificar que, dos 23 CRP, o que apresentou maior número de processos éticos investigados pelo CFP foi o Conselho Regional 6, referente ao estado de São Paulo, responsável por $37,41 \%$ dos casos, seguido da região 8 - estado do Paraná (15,03\%). Todavia, a análise da prevalência mostrou que o estado do Paraná demonstrou maior incidência de processos éticos por psicólogos com CRP ativo, havendo um caso a cada 359 psicólogos inscritos, seguida pelo CRP 11 (Ceará; um processo para cada 409 psicólogos), CRP 16 (Espírito Santo; 1:458) e CRP 12 (Santa Catarina; 1:471). Em outro oposto, as menores prevalências foram encontradas no CRP 13 (Paraíba), 2 (Pernambuco), CRP 17 (Rio Grande do Norte) e CRP 10 (Pará e Amapá).

Nesse sentido cabe destacar que o estado de São Paulo, apesar de ter sido apontado como região com maior frequência de faltas éticas em relação ao número bruto de processos, quando analisada a prevalência, observa-se que apenas $0,12 \%$ dos profissionais inscritos encontram-se nesta estatística. Dessa maneira, visualiza-se a necessidade de que a informação seja contextualizada em termos de número de profissionais registrados no órgão regulador da profissão para que os dados possam ser adequadamente interpretados. Importante ressaltar que os CRPs 15 (Alagoas), 18 (Mato Grosso), 19 (Sergipe), 20 (Amazonas, Acre, Roraima e Rondônia), 21 (Piauí), 22 (Maranhão) e 23 (Tocantins) não apresentaram nenhum processo ético publicado nas edições analisadas. Em seguida, investigou-se os dados de forma mais amplas, considerando-se as cinco Regiões do Brasil (Sul, Sudeste, Centro-Oeste, Nordeste e Norte).
A interpretação dos dados da Tabela 2 permitiu observar que a Região Sudeste é a que mais apresenta percentual de faltas éticas, quando considerado o total de infrações analisadas (53,50\%), seguida da Região Sul (28,32\%). Em contrapartida, a que apresenta menor percentual é a Região Norte $(0,70 \%)$. Porém, é interessante destacar que estes dados se alteram quando são analisadas as prevalências de processos éticos considerando-se o número de profissionais inscritos. A partir desta análise, a Região Sul atinge o primeiro lugar (um processo ético a cada 552 psicólogos), enquanto a Região Sudeste aparece em segundo lugar apresentando uma falta ética a cada 1.028 psicólogos. A Região Norte continua com a posição de menor prevalência de processos éticos (um caso a cada 5.571 psicólogos da região). Em todo o Brasil, a prevalência é de um processo ético a cada 961 psicólogos. Uma discussão mais aprofundada acerca dos dados encontrados será feita posteriormente.

Em seguida, a análise voltou-se ao conteúdo das ementas de cada processo ético apresentado. Ressalta-se que diversas ementas com conteúdo similar ou idêntico foram citadas mais de uma vez e, nesse caso, foram agrupadas. Cabe também informar que as nomenclaturas apresentadas na descrição dos resultados mantiveram-se fiéis àquelas utilizadas pelo Jornal do Federal, assim, os dados permitiram verificar que a maior parte se constitui em processo ético-profissional $(50,70 \%)$, seguida da categoria referente a recurso $(20,63 \%)$ e laudos mal elaborados, parciais e tendenciosos $(8,74 \%)$. As demais, caracterizam-se por categorias menos frequentes, totalizando $19,93 \%$, das mais diferentes naturezas. Dentre

\section{Tabela 2}

Dados agrupados por região brasileira.

\begin{tabular}{lccccc}
\hline Região brasileira & $\begin{array}{c}\text { Conselhos } \\
\text { Regionais } \\
\text { agrupados }\end{array}$ & $\begin{array}{c}\text { Frequência de } \\
\text { faltas éticas } \\
\text { encontradas }\end{array}$ & $\begin{array}{c}\text { Percentual de } \\
\text { faltas éticas por } \\
\text { região }\end{array}$ & $\begin{array}{c}\text { Número de } \\
\text { psicólogos } \\
\text { inscritos em } \\
\text { cada região* }\end{array}$ & $\begin{array}{c}\text { Prevalência } \\
\text { de processos } \\
\text { éticos** }\end{array}$ \\
\hline Sul & 3 & 81 & 28,32 & 44.718 & $1: 552$ \\
Sudeste & 4 & 153 & 53,50 & 157.290 & $1: 1028$ \\
Centro-Oeste & 4 & 19 & 6,64 & 21.393 & $1: 1126$ \\
Nordeste & 9 & 31 & 10,84 & 40.390 & $1: 1303$ \\
Norte & 3 & 2 & 0,70 & 11.142 & $1: 5571$ \\
Total & 23 & 286 & 100 & 274.933 & $1: 961$ \\
\hline
\end{tabular}

Dados coletados em 02 de maio de 2016; *número de psicólogos inscritos nos Conselhos Regionais de cada região, somando os estados pertencentes a cada região; **altas por número de psicólogos de acordo com cada região. 
as encontradas, podem ser citadas: procedimento ético-disciplinar; recurso de processo administrativo; irregularidade em avaliação psicológica, dentre outras posturas inadequadas do profissional da Psicologia; conivência com violação de direitos humanos; divulgação profissional indevida; queixa contra mal atendimento; ofensa do psicólogo ao paciente durante atendimento; maus-tratos a crianças e a adolescentes; facilitação do exercício ilegal da profissão; perturbação da ordem no local de trabalho, causando prejuízo a terceiros; associação da prática psicológica à religiosidade; falsificação de documentos; facilitação de aplicação de testes psicológicos por não psicólogos; clínicas com irregularidades na prestação de serviços de Psicologia.

A proposta seguinte visou avaliar quais princípios éticos foram supostamente violados, a partir dos artigos constantes no Código de Ética Profissional do Psicólogo. Esse levantamento foi baseado na análise de conteúdo das ementas, apresentadas em cada processo analisado. No entanto, convém destacar que dois fatos dificultaram esse tipo de análise. A primeira questão envolveu a ausência de informação quanto à versão do Código de Ética utilizada em cada processo. Diante da constatação de divergências nos conteúdos dos artigos constantes nas duas últimas versões do Código de Ética, referentes aos anos de 1987 e 2005, importante decisão teve que ser tomada. Como exemplo, pode-se citar o artigo de número 21. No Código de 1987, ele é apresentado como "o sigilo protegerá o atendimento em tudo aquilo que o Psicólogo ouve, vê, ou que tem conhecimento como decorrência do exercício da atividade profissional". Já no Código de 2005, o mesmo artigo afirma que

As transgressões dos preceitos deste Código constituem infração disciplinar com a aplicação das seguintes penalidades, na forma dos dispositivos legais ou regimentais:

a) Advertência;

b) Multa;

c) Censura pública;

d) Suspensão do exercício profissional, por até 30 (trinta) dias, ad referendum do Conselho Federal de Psicologia;

e) Cassação do exercício profissional, ad referendum do Conselho Federal de Psicologia.
Como forma de sanar esta dificuldade, buscou-se observar a data de julgamento dos processos éticos, porém, esta ação nem sempre se mostrou produtiva. Considerando todos os procedimentos necessários para a instauração de um processo ético, compreende-se que é preciso algum tempo para sua finalização, tendo em vista que cada etapa possui um prazo, até que o julgamento do caso possa ser encerrado. Especialmente nos anos em que houve a promulgação de uma nova versão do Código de Ética, alguns erros podem ter ocorrido na classificação realizada. Tal fato pode ser citado como uma limitação da pesquisa. Na tentativa de minimizar esse problema, as pesquisadoras buscaram a data do processo, considerando o código em uso.

A terceira dificuldade se baseia na constatação de que somente $12,93 \%(\mathrm{n}=37)$ dos processos analisados informavam qual artigo havia sido infringido (exemplo: artigo $2^{\circ}$ ), de maneira que a maior parte das faltas éticas estudadas não continha informações detalhadas a respeito das ementas (ou motivos), de maneira que o conhecimento gerado através do simples levantamento desse dado seria muito limitado. Os demais $(87,7 \%)$ não apresentavam nenhum tipo de informação referente ao artigo e ementa, inviabilizando sua análise.

Diante da percepção de que esses tipos de alterações de conteúdo também foram observados em outros artigos e incisos, assim como na constatação de que maior objetividade das ementas reportadas nos processos foi encontrada a partir da edição de número

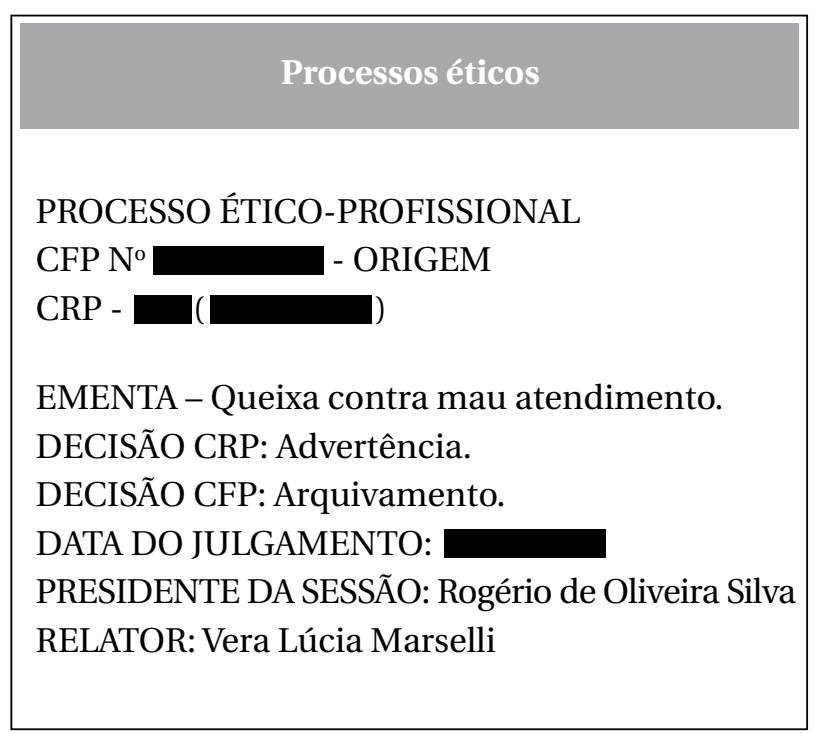

Figura 1

Exemplo de publicação de falta ética encontrada na sessão de Processos Éticos do Jornal do Federal. 
110, uma importante decisão foi tomada, de fazer uso, nessa análise, somente dos três últimos números do jornal, cujas informações mostraram-se mais completas. Assim, uma análise qualitativa, voltada ao levantamento da frequência de ocorrência de cada ementa foi realizada. Na Figura 1, pode-se observar a forma como os dados eram apresentados no Jornal do Federal e, na Tabela 3, o detalhamento destes é exibido.

Como é possível observar na Tabela 3, foram analisadas 57 infrações nas três edições analisadas, as quais representam $20 \%$ dos processos éticos publicados pelo Jornal do Federal no período total considerado (2004-2016). As infrações envolveram 28 diferentes ementas, de diferentes origens, com destaque para problemas relacionados aos laudos psicológicos $(n=27,47,36 \%)$. Cabe destacar que, nestes três números, grande parte dos processos julgados referiu-se à violação de questões voltadas à avaliação psicológica, de maneira a representar $81 \%$ do total de faltas éticas apresentadas no número $110,72 \%$, no número $111 \mathrm{e}$ $56 \%$, no número 112 , do total de faltas éticas constantes em cada número. Perante a predominância de infrações relacionadas à avaliação psicológica, uma segunda análise foi conduzida, separadamente para cada número do jornal.

No número 110 do Jornal do Federal foram encontradas 11 faltas éticas, das quais cinco envolveram o laudo psicológico mal elaborado $(45,4 \%)$ e três estavam relacionadas a irregularidades em avaliação psicológica (de modo geral) e uma tratou especificamente de avaliação para obtenção de Carteira Nacional de Habilitação (CNH). No número 111 houve 18 faltas éticas mencionadas. Destas, observou-se que 11 referiram-se aos laudos mal elaborados $(61,1 \%)$ e duas envolveram irregularidades em avaliação psicológica, porém uma relacionou-se à obtenção de $\mathrm{CNH}$, e outra a concurso público. Por fim, o número 112 exibiu 23 processos éticos, sendo 11 referentes aos laudos psicológicos (47,8\%), um processo relacionado à falsificação de documentos e um, à facilitação de aplicação de testes psicológicos por não psicólogos. Diante desses dados foi possível verificar que importante parte dos processos éticos se voltaram a problemas relacionados à avaliação psicológica (35 das 57 infrações, 61,4\%).

Por fim, considerando-se que, a partir do julgamento dos processos, os conselhos apresentam suas decisões, a análise a seguir buscou classificá-las, tendo-se optado, no presente estudo, pela divisão entre aquelas que se referem aos conselhos regionais e aqueles referentes ao conselho federal. Primeiramente serão descritas as deliberações referentes aos conselhos regionais de todo país. Nesta instância, observou-se que a decisão de arquivamento representa $30,07 \%$ das decisões totais, seguida de advertência $(26,57 \%)$, censura pública (19,58\%), suspensão do exercício profissional por 30 dias $(8,04 \%)$ e pela cassação do exercício profissional (7,34\%). Vale destacar que existem outras determinações descritas nos exemplares verificados, tais como: multas referentes aos valores das anuidades, bem como a combinação de multa com advertência ou censura pública, em menor frequência, previstas no Código de Processamento Disciplinar.

Posteriormente à decisão dos Conselhos Regionais, os casos são analisados pelo Conselho Federal, que toma a decisão final. Desta forma, as decisões do CFP, em grande número, endossam a decisão tomada nas instâncias regionais, em 48,25\% dos processos. Contudo, há também situações em que divergências entre as deliberações de ambos os conselhos são notadas de maneira que, nestes casos, cabe ao Conselho Federal deliberar sobre as decisões finais. Não se faz notar, nesse sentido, a existência de algum padrão, sendo as divergências, as mais diversas possíveis.

\section{Discussão}

O presente estudo teve como objetivo principal analisar as infrações éticas denunciadas como originárias de ações cometidas pelos psicólogos inscritos no CFP. Esta instância possui poderes e direitos instituídos pela legislação, os quais permitem delinear normas de conduta de uma profissão complexa e ampla (Holanda, 1997).

Em uma profissão engajada em cuidar do bem-estar dos indivíduos, a existência do Código de Ética faz-se importante para que determinados princípios não sejam violados (Pereira, \& Pereira Neto, 2003). No caso específico da Psicologia, o Código de Ética prioriza que o exercício profissional esteja em consonância com alguns princípios, notadamente de não causar dano ou prejuízo, causar algum benefício, reconhecimento da limitação de sua atuação e consequente encaminhamento nesses casos, obrigatoriedade do sigilo, expectativa de melhora do paciente e necessidade de conhecimento aprofundado sobre determinado problema e suas formas de superá-lo (Frizzo, 2004), dentre outros. 
Tabela 3

Análise dos conteúdos apresentados nos números 110, 111 e 112 do Jornal do Federal.

\begin{tabular}{|c|c|c|c|c|}
\hline Data & Ano & Número & Ementa & Frequência \\
\hline \multirow{6}{*}{$\begin{array}{l}\text { Maio de } \\
2015\end{array}$} & \multirow[t]{6}{*}{ XXVI } & \multirow[t]{6}{*}{110} & Conivência com violação dos direitos humanos. & 1 \\
\hline & & & Divulgação profissional indevida. & 1 \\
\hline & & & Irregularidade em avaliação psicológica para obtenção de CNH. & 1 \\
\hline & & & Irregularidade em avaliação psicológica. & 2 \\
\hline & & & Laudo mal elaborado. & 5 \\
\hline & & & Queixa contra mau atendimento. & 1 \\
\hline \multirow{8}{*}{$\begin{array}{l}\text { Agosto de } \\
2015\end{array}$} & \multirow[t]{8}{*}{ XXVI } & \multirow[t]{8}{*}{111} & Irregularidade em avaliação psicológica para obtenção de CNH. & 1 \\
\hline & & & Irregularidade em avaliação psicológica em concurso público. & 1 \\
\hline & & & Laudo mal elaborado. & 11 \\
\hline & & & O psicólogo teria ofendido o paciente durante o atendimento. & 1 \\
\hline & & & $\begin{array}{l}\text { A psicóloga na condição de diretora da fundação que atende crianças } \\
\text { e adolescentes teria sido conivente com maus tratos e tratamento } \\
\text { degradante aos menores atendidos. }\end{array}$ & 1 \\
\hline & & & O psicólogo teria facilitado o exercício ilegal da profissão. & 1 \\
\hline & & & $\begin{array}{l}\text { A psicóloga teria perturbado a ordem dos trabalhos na organização } \\
\text { em que era empregada, prejudicando terceiros. }\end{array}$ & 1 \\
\hline & & & $\begin{array}{l}\text { A psicóloga teria afirmado pela internet que atua como psicóloga } \\
\text { cristã e que, nesta condição, presta atendimentos psicológicos a } \\
\text { homossexuais que querem assumir sua heterossexualidade. }\end{array}$ & 1 \\
\hline \multirow[t]{17}{*}{$\begin{array}{l}\text { Março de } \\
2016\end{array}$} & \multirow[t]{17}{*}{ XXVII } & \multirow[t]{17}{*}{112} & $\begin{array}{l}\text { Previsão taxativa de resultados, extrapolando a área de atuação } \\
\text { profissional. }\end{array}$ & 1 \\
\hline & & & $\begin{array}{l}\text { Laudo psicológico sem fundamentação técnica e científica, parcial e } \\
\text { tendencioso. }\end{array}$ & 11 \\
\hline & & & Suposto abuso sexual contra menor durante os atendimentos. & 1 \\
\hline & & & Suposta divergência entre as declarações em juízo e informações ao cliente. & 1 \\
\hline & & & $\begin{array}{l}\text { O psicólogo manteve vínculo afetivo com a ex-esposa de seu cliente, } \\
\text { prejudicando o tratamento. }\end{array}$ & 1 \\
\hline & & & Irregularidades na internação de dependentes químicos involuntários. & 2 \\
\hline & & & $\begin{array}{l}\text { Irregularidades quanto à publicidade e ao repasse de valores à Escola } \\
\text { de Formação de Vigilantes. }\end{array}$ & 1 \\
\hline & & & Falsificação de documentos. & 1 \\
\hline & & & Não realização do registro de pessoa jurídica no CRP-08. & 1 \\
\hline & & & $\begin{array}{l}\text { A clínica contratou profissional não registrado no Conselho Regional } \\
\text { de Psicologia. }\end{array}$ & 1 \\
\hline & & & Violação dos direitos humanos em comunidade terapêutica. & 1 \\
\hline & & & $\begin{array}{l}\text { O psicólogo interveio em atendimento psicoterapêutico de menor, já } \\
\text { acompanhado por outro profissional da categoria. }\end{array}$ & 1 \\
\hline & & & Clínica com irregularidades na prestação de serviços de Psicologia. & 2 \\
\hline & & & $\begin{array}{l}\text { A psicóloga teria influenciado a paciente a alugar um imóvel para a } \\
\text { psicóloga. }\end{array}$ & 1 \\
\hline & & & Facilitar a aplicação de testes psicológicos por não psicólogo. & 1 \\
\hline & & & $\begin{array}{l}\text { O psicólogo teria desrespeitado locais públicos, profissionais de saúde } \\
\text { e conselheiros tutelares. }\end{array}$ & 1 \\
\hline & & & TOTAL & 57 \\
\hline
\end{tabular}

CNH: Carteira Nacional de Habilitação. 
A análise dos processos éticos mostrou que nem sempre esses princípios são seguidos pelos psicólogos. A partir dos dados foi possível observar, em âmbito nacional, que um a cada 961 psicólogos cometeu algum tipo de infração ética, de modo que se torna possível inferir sobre a existência de um número importante de profissionais que não se mostram envolvidos e preocupados em proteger a profissão, praticando ações prejudiciais a ela mesma e aos demais que deveriam beneficiar-se dela. Um alerta a esse respeito foi feito por Holanda (1997), ao afirmar que a Psicologia era uma profissão individualista, no sentido de não demonstrar interesse em compreender os problemas referentes à própria classe profissional e à sociedade em geral. Esta afirmação, apesar de ter sido apresentada há quase duas décadas, parece ainda ser atual frente às faltas éticas cometidas por alguns profissionais da área. Isto, por sua vez, aponta para a contínua relevância do papel dos Conselhos Regionais e Federal no que tange ao zelo nas apurações de condutas éticas, debate referente à excelência na formação profissional e na orientação dos psicólogos (Chiodi, \& Wechsler, 2008; Pereira, \& Pereira Neto, 2003; Soares, 2010).

As análises apresentadas apontaram a presença de faltas éticas na atuação profissional de psicólogos provenientes das diferentes regiões do país. Ao se considerar, de maneira isolada, os números brutos referentes às faltas éticas, um cuidado deve ser tomado em relação à sua contextualização, em relação à região e ao número de profissionais inscritos a fim de não haver conclusões equivocadas. Inicialmente, nota-se que a frequência de casos no estado de São Paulo (Região 6) é a maior em comparação aos demais estados. Entretanto, ao analisar-se as frequências, contextualizando os dados ao número de profissionais inscritos, conclui-se que há maior prevalência de faltas éticas investigadas na Região Sul. Perante uma série de fatores que podem ter exercido influência nos números analisados, podendo-se citar, dentre eles, o trabalho de fiscalização, atuação, orientação e interlocução das ações realizadas pelos Conselhos Regionais. Tais práticas, diferenciadas entre eles, pode acabar estimulando um número maior de representações e denúncias em algumas regiões específicas, as quais podem, inclusive, serem abertas pelo próprio CRP.

Sem a intenção de rotular alguma região quanto às suas posturas éticas, é necessário considerar também outras questões para que os dados sejam melhor contextualizados, tais como: a) o número de psicólo- gos inscritos em seus respectivos CRPs, b) o número de universidades e de formandos em cada região, c) o número de profissionais que não exercem mais a profissão. Do mesmo modo, as questões anteriormente citadas também devem ser consideradas quando tomados os dados referentes à região com menor prevalência de processos éticos (Região Norte - 1 caso a cada 5571 psicólogos), pois estes dados podem ser influenciados pelos mesmos fatores elencados previamente. Dessa maneira, o fato isolado de terem sido encontrados, em menor número, processos éticos em determinadas regiões, não permite que se afirme a inexistência dos mesmos, ou ainda a menor incidência de falta ética. Os fatores mencionados anteriormente se fazem importantes de serem considerados. A análise desses dados poderá, futuramente, oferecer informações mais consistentes e amplas acerca da prevalência das infrações, ainda que o foco desse tipo de estudo seja a conduta geral da classe profissional, em termos nacionais.

Outro ponto relevante a ser discutido, diz respeito aos dados analisados referentes às decisões tomadas pelas instâncias regionais e pela instância federal, as quais mostram-se alinhadas com os critérios estabelecidos tanto pela Resolução $\mathrm{n}^{\circ}$ 006/2007 (CFP, 2007) quanto pelos princípios norteadores do Código de Ética Profissional de Psicologia. Além disso, tomando-se o fato dos temas em que mais concentraram-se as faltas éticas, identificados por uma análise mais qualitativa, mostram que, em relação ao conteúdo, tais faltas envolveram principalmente os princípios éticos de competência, integridade, responsabilidade científica e profissional, respeito pela dignidade e direitos das pessoas, preocupação com o bem-estar do outro e responsabilidade social, conforme também ressaltado por Anache e Reppold (2010).

Notam-se também que os principais comportamentos a serem evitados na prática profissional, os quais ainda se mostram frequentes, envolvem negligência, discriminação, exploração, violência, preconceito, prática ilegal da profissão, conivência com erros e faltas éticas, uso de procedimentos não reconhecidos, emissão de documentos sem fundamentação, emprego questionável de instrumentos psicológicos, dentre outras posturas inadequadas. Tal constatação gera uma demanda por uma atuação mais focada, dos conselhos regionais e federal, em ações voltadas aos aspectos éticos da profissão. Tal necessidade já foi levantada por diversos pesquisadores (Anache, \& Corrêa, 2010; Anache, \& Reppold, 2010; Soares, 2010; Tavares, 2010). 
Verificou-se também que foram identificadas, em número bastante importante, ementas que descrevem as faltas relacionadas à avaliação psicológica. Cabe destacar que o Código de Ética, na versão de 2005, aborda diferentes cuidados fundamentais na prática da Avaliação Psicológica (AP), em especial no artigo 2, notadamente no item $\mathrm{h}$ ("interferir na validade e fidedignidade de instrumentos e técnicas psicológicas, adulterar seus resultados ou fazer declarações falsas"), item k ("ser perito, avaliador ou parecerista em situações nas quais seus vínculos pessoais ou profissionais, atuais ou anteriores, possam afetar a qualidade do trabalho a ser realizado ou a fidelidade aos resultados da avaliação") e item q ("realizar diagnósticos, divulgar procedimentos ou apresentar resultados de serviços psicológicos em meios de comunicação, de forma a expor pessoas, grupos ou organizações"). Outros artigos, como o Artigo 18 também envolve a AP ("o psicólogo não divulgará, ensinará, cederá, emprestará ou venderá a leigos, instrumentos e técnicas psicológicas que permitam ou facilitem o exercício ilegal da profissão”).

Tal cuidado vem ao encontro de um movimento de retomada da AP, iniciado em 2003, a partir da criação de um Satepsi, que se deu diante da observação da quantidade de processos éticos envolvendo a avaliação psicológica (Primi, \& Nunes, 2010). No entanto, a incidência de processos ainda nessa área específica, mostra que parte dos problemas ainda se mantêm, mais de uma década depois das medidas adotadas pelo CFP. Ainda que diferentes avanços tenham sido notados (Noronha, Carvalho, Miguel, Souza \& Santos, 2010), especificamente em relação ao aumento no número de pesquisas publicadas, no número de instrumentos disponíveis, na criação de laboratórios de pesquisa e na ampliação de discussões sobre a temática (Padilha, Noronha, $\&$ Fagan, 2007).

Por fim, outra constatação importante refere-se ao número elevado de problemas relacionados à elaboração de laudos psicológicos e documentos escritos, historicamente questionados devido à baixa qualidade apresentada e pelos diagnósticos equivocados encontrados nesses documentos (Alves, 2009). Diante desse quadro, inúmeros pesquisadores têm voltado sua atenção para a formação do profissional nos cursos de graduação. Especificamente no caso da atuação na área da AP, esse processo, tem se mostrado insuficiente, superficial e inconsistente, na medida em que se apresenta fundamentada, muitas vezes, conforme já apontado, no propósito único de aplicar e de avaliar testes sem o uso de uma análise crítica e mais apurada (Noronha, Carvalho, Miguel, Souza, \& Santos, 2010). Nesse sentido, ainda que importantes avanços venham sendo notados na área, parte dos problemas ainda persistem (Hutz, \& Bandeira, 2003).

Diferentes autores têm apontado uma relação entre atuações profissionais impróprias e formação inconsistente na área (Noronha, Primi \& Alchieri, 2005), baseados na constatação de que a importância do investimento na formação profissional ampara-se, segundo Noronha (2009), na concepção de que, "quanto melhor a formação recebida pelos estudantes em sua preparação profissional, tanto melhor sua possibilidade de fazer um bom uso dos instrumentos e da avaliação como um todo" (p. 78). Entretanto, conforme salientado por Hutz e Bandeira (2003), a formação em avaliação psicológica não deve ocorrer somente na graduação. Segundo os autores, é necessário que o profissional, além desta, realize cursos de atualização, invista na sua capacitação (por exemplo, por meio da inserção em programas de pós-graduação), visando a continuar a sua formação e a aprimorar o conhecimento pertinente à construção e ao uso dos instrumentos de avaliação.

Isso porque o crescimento do número de cursos de Psicologia ofertados no país não tem sido acompanhado, infelizmente, pelo cuidado em relação à qualidade dos cursos e dos profissionais formados (Mendes, Nakano, Silva, \& Sampaio, 2013), de maneira que estes nem sempre atingem a condição desejada (Calais, \& Pacheco, 2001). Dentre os motivos, a literatura tem destacado a necessidade de redução de custos, alcançada por meio da contratação de professores menos experientes e qualificados, a queda da exigência de um currículo mínimo obrigatório, ficando as instituições livres para organizá-lo da forma que melhor compreenderem (Alves, 2009), a ausência de avaliações sistemáticas sobre a qualidade da formação (Noronha, \& Alchieri, 2002), a diminuição considerável no número de disciplinas referentes à avaliação psicológica (Reppold, \& Serafini, 2010), bem como falhas no conhecimento de noções de como se elabora um documento e de como seus resultados podem ser utilizados na compreensão do indivíduo (Lohr, 2011). 


\section{Considerações finais}

A história da Psicologia, no Brasil, tem sido construída por meio de esforços contínuos dos profissionais (Rechtman, 2015), notadamente por meio de inúmeras ações que vêm sendo conduzidas para que a Psicologia assuma, definitivamente, o caráter de ciência, sendo assim reconhecida socialmente, e que seu ensino e prática sejam embasados em condutas éticas (Soares, 2010). Dentre estas ações destaca-se tanto a criação como a atuação dos Conselhos Regionais e do Conselho Federal, instâncias de representação máxima dos profissionais da área (Holanda, 1997). Ainda que importantes avanços tenham sido alcançados nas últimas décadas, alguns focos ainda merecem maior investimento, notadamente a área de ensino e formação, ética e avaliação psicológica. Especificamente em relação à última, apesar de a formação em avaliação psicológica estar sendo revista, ainda são necessários muitos os investimentos de docentes e de pesquisadores na área para que se obtenha a melhoria da sua qualidade no país (Noronha, 2006), de forma que se torna imprescindível que os profissionais se tornem mais ativos, efetivos e regulares no consumo da literatura que se produz nacionalmente e internacionalmente (Noronha, \& Reppold, 2010), em um processo constante de capacitação profissional.

Ao se propor a análise dos processos éticos, elencados pelo CFP, a fim de obter dados acerca dos problemas e dificuldades que ainda marcam a atuação na área, algumas limitações do trabalho merecem ser citadas. Dificuldades técnicas com arquivos que apresentaram problemas de visualização, falta de acesso ao conteúdo de alguns exemplares do jornal do CFP, assim como a ausência de informações detalhadas acerca dos processos - limitação essa que é compreendida pelos trâmites sigilosos dos processos e a mudança do formato de apresentação dos casos (em relação ao tipo de informação disponibilizada), impossibilitaram uma análise mais aprofundada e completa dos processos éticos profissionais.

Espera-se, entretanto, que os resultados aqui encontrados possam contribuir com o aprimoramento da profissão a partir da apresentação e análise objetiva das faltas éticas, principalmente se considerarmos que um eixo norteador das mudanças almejadas consiste na reflexão sobre o processo de formação, tornando-se necessário o desenvolvimento de medidas educativas voltadas aos profissionais e estudantes (Noronha, Primi, \& Alchieri, 2004). No entanto, outras ações também se fazem necessárias, notadamente aquelas voltadas aos profissionais atuantes na área, visto que a ética consiste em uma postura individual. Ainda que tal psicólogo tenha sido formado dentro de um processo que tenha priorizado a formação ética, a prática pode ser bem diferente do domínio teórico que ele possui.

Pode-se, desse modo, observar que a melhora da área envolve uma preocupação "com os avanços metodológicos, tecnológicos e teóricos, com a qualificação e normatização dos instrumentos disponíveis, com a necessidade de contextualização dos resultados obtidos, com a validade consequencial e clínica dos testes e com a relevância social das avaliações realizadas" (Reppold, 2011, p. 23). Dentro dessa perspectiva, faz-se necessário que ações em âmbito individual e coletivo sejam realizadas, de modo que caberia: aos profissionais que estão na prática a compreensão da necessidade de se manterem atualizados e de investirem em suas próprias capacitações, aos docentes promover a reflexão contínua sobre a qualidade das formações que oferecem (Noronha et al., 2010) e, também, aos conselhos a realização de ações voltadas tanto aos profissionais da Psicologia quanto à sociedade. Por fim, pode-se concluir que um conjunto de ações, tais como as aqui apresentadas, podem favorecer a diminuição dos problemas de natureza ética.

\section{Referências}

Alves, I. C. B. (2009). Reflexões sobre o ensino em avaliação psicológica na formação do psicólogo. In C. S. Hutz (Org.), Avanços e polêmicas em avaliação psicológica (pp. 217-242). São Paulo, SP: Casa do Psicólogo.

Anache, A. A., \& Corrêa, F. B. (2010). As políticas do Conselho Federal de Psicologia para a avaliação psicológica. In A. A. Santos, A. A. Anache, A. E. Villemor-Amaral, B. S. V. Welang, C. T. Reppold, C. H. S. Nunes et al.(Orgs.), Avaliação psicológica: Diretrizes para a regulamentação da profissão. (Vol.1, pp. 19-39). Brasília, DF: Conselho Federal de Psicologia.

Anache, A. A., \& Reppold, C. T. (2010). Avaliação psicológica: Implicações éticas. In A. A. Santos, A. A. Anache, A. E. Villemor-Amaral, B. S. V. Welang, C. T. Reppold, C. H. S. Nunes et al. (Orgs.). Avaliação psicológica: Diretrizes para a regulamentação da profissão. (Vol.1, pp. 57-86). Brasília, DF: Conselho Federal de Psicologia. 
Bastos, A. V. B., \& Gomide, P. I. C. (1989). O psicólogo brasileiro: Sua atuação e formação profissional. Psicologia: Ciência e Profissão, 9(1), 6-15. https://doi.org/10.1590/S1414-98931989000100003

Calais, S. L., \& Pacheco, E. M. C. (2001). Formação de psicólogos: Análise curricular. Psicologia Escolar e Educacional, 5(1), 11-18. https:// doi.org/10.1590/S1413-85572001000100002

Chiodi, M. G., \&Wechsler, S. M. (2008). Avaliação psicológica: Contribuições brasileiras. Boletim Academia Paulista de Psicologia, 2(8), 197-210. Recuperado de http://www.redalyc.org/pdf/946/94628208.pdf

Conselho Federal de Psicologia - CFP. (2007). Resolução CFP No 06/2007. Institui o Código de Processamento Disciplinar. Recuperado de http://site.cfp.org.br/wp-content/uploads/2012/07/resolucao2007_6.pdf

Frizzo, N. P. (2004). Infrações éticas, formação e exercício profissional em Psicologia (Dissertação de mestrado). Universidade Federal de Santa Catarina, Florianópolis, SC.

Holanda, A. (1997). Os conselhos de psicologia, a formação e o exercício profissional. Psicologia: Ciência e Profissão, 17(1), 3-13. https:// doi.org/10.1590/s1414-98931997000100002

Hutz, C. S., \& Bandeira, D. R. (2003). Avaliação psicológica no Brasil: Situação atual e desafios para o futuro. In O. H. Yamamoto, \& V. V. Gouveia (Orgs.), Construindo a psicologia brasileiro: Desafios da ciência e prática psicológica (pp. 261-275). São Paulo, SP: Casa do Psicólogo.

Lohr, S. S. (2011). Avaliação psicológica na formação do profissional da Psicologia: Algumas reflexões. In Conselho Federal de Psicologia. Ano da avaliação psicológica: Textos geradores (pp. 143-149). Brasília, DF: o Autor. Recuperado de http://site.cfp.org.br/wp-content/uploads/2013/04/anodaavaliacaopsicologica_prop8.pdf

Mendes, L.S., Nakano, T. C., Silva, I.B., \&Sampaio, M.H.L. (2013). Conceitos de avaliaçãopsicológica: Conhecimentode estudantes e profissionais. Psicologia: Ciência e Profissão, 33(2), 428-445. https://doi.org/10.1590/S1414-98932013000200013

Noronha, A. P. P. (2006). Formação em avaliação psicológica: Uma análise das disciplinas. Interação em Psicologia, 10(2), 245-252. https://doi.org/10.5380/psi.v10i2.7681

Noronha, A. P. P. (2009). Testes psicológicos: Conceito, uso e formação do psicólogo. In C. S. Hutz (Org.), Avanços $e$ polêmicas em avaliação psicológica (pp. 71-92). São Paulo, SP: Casa do Psicólogo.

Noronha, A. P. P., \& Alchieri, J. C. (2002). Reflexões sobre os instrumentos de avaliação psicológica. In R. Primi (Org.), Temas em avaliação psicológica (pp. 7-16). Campinas, SP: Ibap.

Noronha, A. P. P., Carvalho, L. F., Miguel, F. K., Souza, M., \& Santos, M. A. (2010). Sobre o ensino de avaliação psicológica. Avaliação Psicológica, 9(1), 139-146. Recuperado de http://www.redalyc.org/pdf/3350/335027281015.pdf

Noronha, A. P. P., Primi, R., \& Alchieri, J. C. (2004). Parâmetros psicométricos: Uma análise de testes psicológicos comercializados no Brasil. Psicologia: Ciência e Profissão, 24(4), 88-99. https://doi.org/10.1590/S1414-98932004000400011

Noronha, A. P. P., Primi, R., \& Alchieri, J. C. (2005). Instrumentos de avaliação mais conhecidos/utilizados por psicólogos e estudantesdepsicologia. Psicologia:Reflexãoe Crítica, 18(3),390-401.https://doi.org/10.1590/S1413-73722005000100015

Noronha, A. P. P., \& Reppold, C. T. (2010). Considerações sobre a avaliação psicológica no Brasil. Psicologia: Ciência e Profissão, 30(n esp), 192-201. https://doi.org/10.1590/S1414-98932010000500009

Padilha, S., Noronha, A. P. P., \& Fagan, C. Z. (2007). Instrumentos de avaliação psicológica: uso e parecer de psicólogos. Avaliação Psicológica, 6(1), 69-76. Recuperado de http://pepsic.bvsalud.org/scielo.php?script=sci_arttext\&pid=S1677-04712007000100009

Pereira, F. M., \& Pereira Neto, A. (2003). O psicólogo no Brasil: notas sobre seu processo de profissionalização. Psicologia em Estudo, 8(2), 19-27. https:// doi.org/10.1590/s1413-73722003000200003

Primi, R, \& Nunes, C. H. S. (2010). O Satepsi: desafios e propostas de aprimoramento. In A. A. Santos, A. A. Anache, A. E. Villemor-Amaral, B. S. V. Welang, C. T. Reppold, C. H. S. Nunes, C. H. S, M. Tavares et al.(Orgs.), Avaliação psicológica: Diretrizes para a regulamentação da profissão. (Vol.1, pp. 129-148). Brasília, DF: Conselho Federal de Psicologia.

Rechtman, R. (2015). O futuro da psicologia brasileira: uma questão de projeto político. Revista Psicologia, Diversidade e Saúde, 4(1), 69-77. https:// doi.org/10.17267/2317-3394rpds.v4i1.578

Reppold, C. T. (2011). Qualificação da avaliação psicológica: critérios de reconhecimento e validação a partir dos direitos humanos. In A. A. Santos, A. A. Anache, A. E. Villemor-Amaral, B. S. V. Welang, C. T. Reppold, C. H. S. Nunes et al. (Orgs.), Avaliação psicológica: Diretrizes para a regulamentação da profissão. (Vol.1, pp. 21-28). Brasília, DF: Conselho Federal de Psicologia. 
Reppold, C. T., \& Serafini, A. J. (2010). Novas tendências no ensino da avaliação psicológica. Avaliação Psicológica, 9(2), 323-329. Recuperado em de http://www.redalyc.org/html/3350/335027283016/

Soares, A. R. (2010). A Psicologia no Brasil. Psicologia: Ciência e Profissão, 30(n esp), 8-41. https://doi.org/10.1590/ S1414-98932010000500002

Tavares, M. (2010). Da ordem social da regulamentação da Avaliação Psicológica e do uso dos testes. In A. A. Santos, A. A. Anache, A. E. Villemor-Amaral, B. S. V.Welang, C. T. Reppold, C. H. S. Nunes et al. (Orgs.). Avaliação psicológica: Diretrizes para a regulamentação da profissão. (Vol.1, pp. 31-56). Brasília, DF: Conselho Federal de Psicologia.

\section{Priscila Zaia}

Doutoranda em Psicologia pela Pontifícia Universidade Católica, Campinas - SP. Brasil.

E-mail: priscilazaia@gmail.com

\section{Karina da Silva Oliveira}

Doutoranda em Psicologia pela Pontifícia Universidade Católica, Campinas - SP. Brasil.

E-mail: karina_oliv@yahoo.com.br

\section{Tatiana de Cássia Nakano}

Docente do Programa de Pós-Graduação em Psicologia da Pontifícia Universidade Católica, Campinas - SP. Brasil. E-mail: tatiananakano@hotmail.com

Endereço para envio de correspondência:

Departamento de Pós-Graduação em Psicologia da PUC-Campinas. Avenida John Boyd Dunlop, s/n. Jardim Ipaussurama. CEP: 13060-904. Campinas - SP. Brasil.

Recebido 14/09/2016

Reformulado 11/11/2017

Aprovado 29/11/2017

Received 09/14/2016

Reformulated $11 / 11 / 2017$

Approved 11/29/2017

Recibido 14/09/2016

Reformulado 11/11/2017

Aceptado 29/11/2017

Como citar: Zaia, P., Oliveira, K. S., \& Nakano, T. C. (2018). Análise dos processos éticos publicados no jornal do Conselho Federal de Psicologia. Psicologia: Ciência e Profissão, 38(1), 8-21. https://doi.org/10.1590/1982-3703003532016

How to cite: Zaia, P., Oliveira, K. S., \& Nakano, T. C. (2018). Analysis of ethical claims published in the Psychology's Federal Council journal. Psicologia: Ciência e Profissão, 38(1), 8-21. https://doi.org/10.1590/1982-3703003532016

Cómo citar: Zaia, P., Oliveira, K. S., \& Nakano, T. C. (2018). Análisis de los procesos éticos publicados en el diario del Consejo Federal de Psicología. Psicologia: Ciência e Profissão, 38(1), 8-21. https://doi.org/10.1590/1982-3703003532016 